\title{
New protocol for the indirect regeneration of the Lilium ledebourii Bioss by using bulb explants
}

\author{
Sina Ghanbari - Barat Ali Fakheri - Mohammad Reza Naghavi - Nafiseh Mahdinezhad
}

Received: 14 May 2018 / Revised: 11 June 2018 / Accepted: 11 June 2018

(C) Korean Society for Plant Biotechnology

\begin{abstract}
Lilium ledebourii Bioss is a wild species of Lilium, which grows naturally in some provinces of Iran. Previous studies on Lilium tissue culture have been linked to direct regeneration and a few studies have been conducted on indirect regeneration, which has been studied under bright conditions. In this study, for the first time in the world, all the stages of indirect regeneration (callus induction, shoot and root induction) have been studied under dark conditions. Callus formation and the regeneration levels of $L$. Ledebourii Bioss were examined for three replicates in an MS (Murashige and Skoog) medium with different hormonal compositions and by using a factorial experiment in the framework of a completely random plan. For callus initiation, 2,4-D and kinetin hormones were used in five and four levels, respectively, as auxin and cytokinin. Results showed that the highest percentage of the callus was found in $3 \mu \mathrm{M}$ of 2,4-D and 0.5 $\mu \mathrm{M}$ of kinetin. In terms of callus wet weight, the highest amount was found in $3 \mu \mathrm{M}$ of 2,4-D and $0.5 \mu \mathrm{M}$ of kinetin. In addition, in terms of diameter, the highest amount was found in $3 \mu \mathrm{M}$ of $2,4-\mathrm{D}$, and $0.5 \mu \mathrm{M}$ of kinetin. In summary, the 2,4-D hormone had a major impact on the percentage of regeneration increase so that the best response was related to the composition of $3 \mu \mathrm{M}$ of 2,4-D, and $0.1 \mu \mathrm{M}$ of kinetin. This study contended that auxin and cytokinin can induce long shoots and roots through cell elongation in dark condition.
\end{abstract}

S. Ghanbari $(\bowtie) \cdot$ Barat Ali Fakheri $\cdot$ Nafiseh Mahdinezhad Department of Plant Breeding and Biotechnology, Faculty of Agriculture, University of Zabol, Zabol, Iran e-mail: sina_qanbari@yahoo.com, sina.qanbari@gmail.com

M. R. Naghavi

Department of Agronomy and Plant Breeding, College of Agriculture and Natural Resources, University of Tehran, Karaj, Iran

S. Ghanbari $(\bowtie) \cdot M$. R. Naghavi

Plant Bank, Iranian Biological Resource Center (IBRC), ACECR, Tehran, Iran

e-mail: sina_qanbari@yahoo.com,sina.qanbari@gmail.com
Keywords Callus, Indirect regeneration, Hormone, in vitro, Lilium ledebourii Bioss

\section{Introduction}

L. ledebourii Bioss is a species of the Lilium family and it is a herbaceous, monocotyledonous, and permanent plant. This species, which is the rarest species of Lilium, grows in a few areas of Iran, such as the Ardebil, Mazandaran, and Gilan Provinces. Liliums are usually reproduced through their flakes and, in general, $3 \sim 5$ bulbs are reproduced out of each flake. One of the major shortcomings of the traditional reproduction of Lilium is its low output. It is tough to access the non-polluted bulb or new hybrids in a very short period. Thus, in vitro regeneration methods are highly recommended (Arzate et al. 1997). Recently, tissue culture has been widely utilized instead of plant propagation. In this method, in order to initiate growth, a small amount of differentiated and separated organ or tissue as explant is located in an artificial environment (Chawla 2000). During the commencement of growing within a nutria environment, the non-activated, differentiated, and divided sample shifts and gets involved in the meristem state. In this regard, dedifferentiation is put into words as the return of the adult cell to the meristem stage and the formation of the callus tissue (Chawla 2002). Moreover, the ability of the callus tissue to significantly differ in the adult plant or adult plan organ is called redifferentiation. The dedifferentiation of explants is conducted in a hormonal medium and then a callus is produced. The hormones are organic compounds that are naturally synthesized in plants and have a major effect on growth. Two main groups that are used in the lab tissue include cytokinins and auxins, which can regulate plant growth (Eudes et al. 2003). Dividing the cell and callus formation are the features of auxins. To infuse the callus, a strong auxin, namely the 2,4-dichloro-phenoxyacetic 
acid (2,4-D) hormone is used. Naphthalene acetic acid (NAA) and indole acetic acid (IAA) are the other auxins. Cytokinins are the derivatives of adenines that assist in physiology processes and have an important role to play in the induction of branching if these hormones, which are used with auxins, can divide cells at high speed (Chawla 2000). It is also worthwhile to mention that the storage solutions IAA and kinetin are sensitive and inconstant to light; therefore, they are kept in the dark. The most widely usable cytokines are kinetin, benzyl adenine (BA), and benzyl amino porin (BAP). In certain species, high concentrations of auxin and low levels of cytokinin in the culture media can promote the callus production process (Chawla 2002). Other important factors in the formation of the callus include the plant genotype, the composition of culture media, and the physical variables of growth (light and temperature). Furthermore, the light's effects on the formation of the callus depend on the species of the plant. In certain cases, light, and, in certain cases, darkness, are required. Usually temperatures of $22 \sim 28^{\circ} \mathrm{C}$ are fruitful for the production of the callus (Chawla 2000). The callus formation in monocotyledonous plants is lower than dicotyledonous plants. Simmonds and Cumming (1976) reported that the highest amount of callus induction from the bulb in Lilium explants takes form in the MS medium that contains $5 \mu \mathrm{M}$ of 2,4-D and $5 \mu \mathrm{M}$ benzyl adenine. Chang et al. (2000) concluded that the best medium for callus initiation in $L$. speciosum was an MS medium containing $3 \mu \mathrm{M}$ 2,4-D along with $0.25 \mu \mathrm{M}$ BA. Mori et al. (2005), in a study of 30 breeds of Lilium, reported that callus formation occurred after two months. They stated that 24 out of 30 breeds positively responded to callus formation and the highest amount of callus induction was obtained from bulb explants. Saetiew and Umamanit (2015), in their study of $L$. formelongo, found that in an MS medium containing $1 \mu \mathrm{M}$ NAA and $0.5 \mu \mathrm{M}$ TDZ, the highest amount of callus formation took place after four weeks, and the MS medium containing $0.5 \mu \mathrm{M}$ IAA was effective for root induction. In this method, the morphogenesis process can be controlled in vitro by altering the amount and type of hormones. The reduction of auxin and addition of cytokinin concentration are also needed in the production of stems triggered by a callus tissue (Chawla 2002). The next step involves rooting the produced stems. The exemptions consist of IBA and IAA alone or in combination with a small amount of cytokine, which are important in the formation of root primordia. Kanchanapoom et al. (2011) concluded that the best compound for $L$. longiforum organogenesis is $1.5 \mu \mathrm{M} \mathrm{NAA}$ and $15 \mu \mathrm{M} \mathrm{BA}$, and for rooting, it is $5 \mu \mathrm{M}$ IBA. Skoric et al. (2012) found that organogenesis in the L. martagon bulbs is performed by using an MS medium that contains $0.2 \mu \mathrm{M}$ BAP along with $0.25 \mu \mathrm{M}$ NAA. Kamo and Hee Han (2002) also reported that the highest amount of callus induction was obtained from a combination of picloram and dicamba on L. longiflorum.

Few studies have been performed on L. ledebourii Bioss (Azadi et al. 2007, Azadi 2003, Padasht Dahkaei 2005) and while the studies carried out heretofore on the indirect regeneration of plants have not been reported inside dark conditions, the purpose of this study was to investigate the indirect regeneration of the native plant in completely dark conditions.

\section{Materials and Methods}

This study was carried out in the culture laboratory of the Iranian Biological Resource Center. In the process of the disinfection of the plants, the contaminated or injured flakes were removed, and then, the intact flakes were separated from the lower parts of bulbs and were placed under a flow of water for six hours. After washing, the flake pieces were placed into $5 \%$ benomyl solution for 75 minutes. Then, the flakes were washed once again and were placed into $70 \%$ alcohol for one minute; after that, they were washed once again with distilled water and were put in a solution containing 5\% hypochlorite for 25 minutes. Afterwards, the dish containing explants was washed three times with sterile distilled water under completely sterile conditions. In this study, MS (Murashige and Skoog 1962) was the basic medium and the following treatments were used to study callus formation and regeneration. These two experiments were conducted in factorial experiments based on a complete random block design with three repetitions (in the current study, in each replication, forty explants were assessed). In these experiments, different hormone levels were used as treatments. The flakes were cut into 5-mm pieces and to produce callus, they were cultured in vitro in the MS medium containing $30 \mathrm{~g} \mathrm{l}^{-1}$ sucrose and $7 \mathrm{~g} \mathrm{l}^{-1}$ agar, along with five levels $(0,1,2$, 3 , and $4 \mu \mathrm{M})$ of 2,4-D and four levels $(0,0.1,0.5$, and $1 \mu \mathrm{M})$ of kinetin; they were also cultured in a mixture of the 2,4-D hormone in five levels $(0,1,2,3$, and $4 \mu \mathrm{M})$ and BA hormone in four levels $(0,0.1,0.5$, and $1 \mu \mathrm{M})$. These media were placed in light for eight hours and 16 hours in darkness at $25 \pm 2^{\circ} \mathrm{C}$; they were re-cultured every two weeks. After 18 days, notes of callus percentage, callus number, and callus diameter were taken every five days. 
For stem elongation, the existing callus tissue of the MS media with $3 \mu \mathrm{M}$ of $2,4-\mathrm{D}$ and $0.5 \mu \mathrm{M}$ of kinetin at $25^{\circ} \mathrm{C}$ is located under the two light conditions with a light intensity of approximately 300 lux and darkness. The stems appeared under the condition of darkness within $3 \sim 5$ weeks. After one week of stem appearance, the roots appeared and were kept under incubation and the same conditions; then, the seedlings rooted were transferred to the greenhouse and all the establishment and adaptation stages were implemented for them. Since the stemming and rooting processes took place in darkness, before being transferred to the greenhouse for the completion of the physiological process and the formation of chlorophyll, they were placed in a germinator with a temperature of $25 \pm 2^{\circ} \mathrm{C}$ and kept for 8 hours in darkness and for 16 hours in light, with a light intensity of 300 lux. Forty-five days after the primary culturing of explants, given that shoots and roots induced were formed from the callus, notes on the root number, root percentage, bulb number, and bulb percentage were taken every five days. Then, experimental data was entered in the MS Excel software. All the data was analyzed by the SAS software. Finally, a comparison between the average data of all the experiments was made based on the Duncan multi-range test.

\section{Results}

After keeping the explants in the callus initiation environment for several days, they swelled gradually. After $16 \sim 17$ days, the explants started callus formation. Within the third week, callus formation was observed in some samples and the percentage of callus formation gradually increased. At the end of the $30^{\text {th }}$ day, in order to compare the treatments, factors such as the percentage, weight, and diameter of the callus, which were formed in these treatments, were measured. The results showed that callus formation did not happen in any of the compositions related to the different concentrations of auxin and cytokinin (BA and 2,4-D), but it happened in the composition of 2,4-D and kinetin. The analysis of variance showed that the type of hormone, level of hormone, and their interactions had a significant effect $(\mathrm{P} \leq 0.01)$ on callus formation. In other words, 2,4-D and kinetin had a significant effect $(\mathrm{P} \leq 0.01)$ on callus formation (Fig. 1). The concentrations of $3 \mu \mathrm{M}$ of 2,4-D and $0.5 \mu \mathrm{M}$ of kinetin showed the highest callus percentage $(66.67 \%)$, weight $(19.43 \pm 0.4 \mathrm{~g})$, and diameter $(18.58 \pm 0.35 \mathrm{~mm})$ (Table 1). Therefore, this concentration had the highest level of callus formation. Treatments containing $2 \mu \mathrm{M}$ of 2,4-D along with $0.5 \mu \mathrm{M}$ of kinetin

Table 1 Interaction of 2,4-D $(\mu \mathrm{M})$ and kinetin $(\mu \mathrm{M})$ levels on callus formation of L. ledebourii Bioss in dark condition

\begin{tabular}{|c|c|c|c|c|}
\hline $2,4-\mathrm{D}(\mu \mathrm{M})$ & Kinetin $(\mu \mathrm{M})$ & Percent of Callus & Callus weight & Callus diameter \\
\hline 0 & 0 & 0 & $0 \mathrm{~g}$ & of \\
\hline 0 & 0.1 & 0 & $0 \mathrm{~g}$ & of \\
\hline 0 & 0.5 & 0 & $0 \mathrm{~g}$ & of \\
\hline 0 & 1 & 0 & $0 \mathrm{~g}$ & of \\
\hline 1 & 0 & 0 & $0 \mathrm{~g}$ & of \\
\hline 1 & 0.1 & 0 & $0 \mathrm{~g}$ & of \\
\hline 1 & 0.5 & 0 & $0 \mathrm{~g}$ & of \\
\hline 1 & 1 & 0 & $0 \mathrm{~g}$ & Of \\
\hline 2 & 0 & 0 & $0 \mathrm{~g}$ & of \\
\hline 2 & 0.1 & 0 & $0 \mathrm{~g}$ & of \\
\hline 2 & 0.5 & 8 & $4.60 \pm 0.1 \mathrm{f}$ & $4.82 \pm 0.36 \mathrm{e}$ \\
\hline 2 & 1 & 26.67 & $7.50 \pm 0.1 \mathrm{c}$ & $12.61 \pm 0.12 \mathrm{c}$ \\
\hline 3 & 0 & 0 & $0 \mathrm{~g}$ & of \\
\hline 3 & 0.1 & 26.67 & $8.38 \pm 0.12 b$ & $14.69 \pm 018 \mathrm{~b}$ \\
\hline 3 & 0.5 & 66.67 & $19.43 \pm 0.4 \mathrm{a}$ & $18.58 \pm 0.35 \mathrm{a}$ \\
\hline 3 & 1 & 26.67 & $6.23 \pm 0.11 \mathrm{~d}$ & $12.41 \pm 0.07 \mathrm{c}$ \\
\hline 4 & 0 & 0 & $0 \mathrm{~g}$ & of \\
\hline 4 & 0.1 & 8 & $4.80 \pm 01 \mathrm{e}$ & $5.90 \pm 0.05 \mathrm{~d}$ \\
\hline 4 & 0.5 & 0 & $0 \mathrm{~g}$ & of \\
\hline 4 & 1 & 0 & $0 \mathrm{~g}$ & Of \\
\hline
\end{tabular}

Any two means that didn't share a common letter differ significantly from each other at $1 \%$ probability level. 

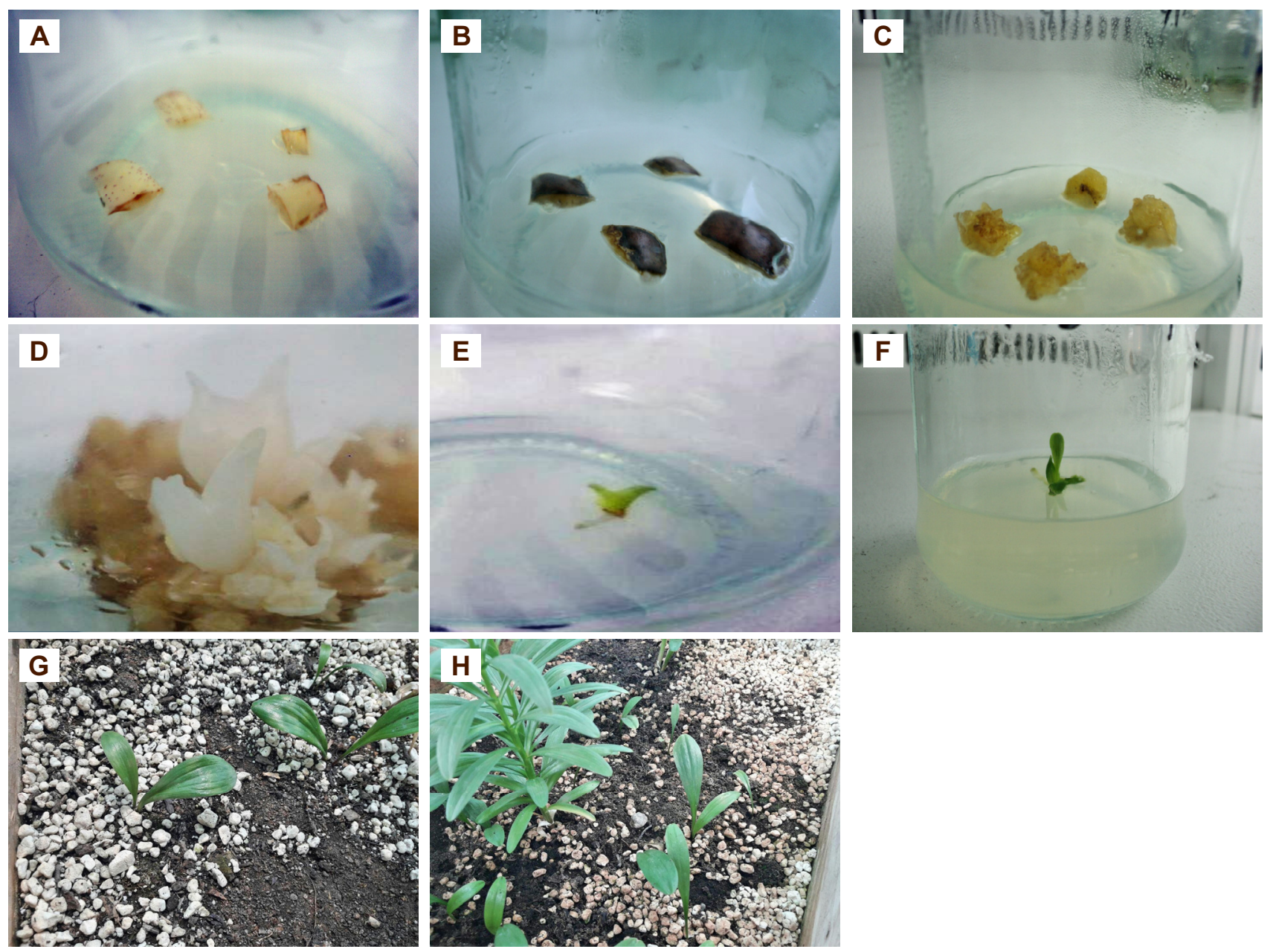

Fig. 1 A: Explants culture. B: Swollen explants. C: Callus produced from the composition of $3 \mu \mathrm{M} 2,4-\mathrm{D}$ and 0.5 $\mu \mathrm{M}$ kinetin. D: Shoot induce from callus produced in darkness. E: Change in the color of a formed organ from white to green after being placed in light. F: The whole plant. G: Transfer to Soil, H; Grow the plant

as well as $4 \mu \mathrm{M}$ of 2,4-D along with $0.1 \mu \mathrm{M}$ kinetin showed the lowest levels of callus formation. Callus formation did not happen in the composition of 2,4-D and of BA. The effects of 2,4-D and kinetin concentrations, and their interaction with regeneration was significant $(\mathrm{P}$ $\leq 0.01)$. The highest regeneration percentage $(76.67 \%)$ was related to the hormonal treatment of $3 \mu \mathrm{M}$ of 2,4-D along with $0.1 \mu \mathrm{M}$ of kinetin (Table 1 and Fig. 1). In addition, this treatment had the highest amount of shoot $(18.67 \pm$ 1.15) (Table 2). The effects of the 2,4-D and kinetin concentrations, and their interaction with roots percentage and numbers were significant $(\mathrm{P} \leq 0.01)$. The highest root percentage (81.67) and number $(19.33 \pm 0.57)$ were related to the concentration of $3 \mu \mathrm{M}$ of 2,4-D along with $0.5 \mu \mathrm{M}$ of kinetin (Table 2 and Fig. 1).

\section{Transfer to Soil}

After seedling adaptation to the perlite culture beds with the PittMoss product, the seedlings were transferred to soil-bearing pots outside the greenhouse (Fig. $1 \mathrm{G}$ and $1 \mathrm{H}$ ).

\section{Discussion}

In spite of applying different treatments, such as alcohol, sodium hypochlorite, mercury hypochlorite, and heat treatments, Mohammadi Dehcheshmeh (2005) and Gholami (2007) did not succeed in obtaining intact explants from Fritillaria (Fritillaria imperialis L.) flakes; so, they used petal explants. They attributed their failure to internal bacterial contamination and as a result, they emphasized on applying noncallus explants for the regeneration of Fritillaria. The results 
Table 2 Interaction of 2,4-D $(\mu \mathrm{M})$ and kinetin $(\mu \mathrm{M})$ levels on Shoot and Root induction of L. ledebourii Bioss in dark condition

\begin{tabular}{|c|c|c|c|c|c|}
\hline $\begin{array}{r}2,4-\mathrm{D} \\
(\mu \mathrm{M})\end{array}$ & $\begin{array}{c}\text { Kinetin } \\
(\mu \mathrm{M})\end{array}$ & Percent of shoot & Number of shoot & Percent of Root & Number of Root \\
\hline 0 & 0 & 0 & $0 \mathrm{e}$ & 0 & of \\
\hline 0 & 0.1 & 0 & $0 \mathrm{e}$ & 0 & of \\
\hline 0 & 0.5 & 0 & $0 \mathrm{e}$ & 0 & of \\
\hline 0 & 1 & 0 & $0 \mathrm{e}$ & 0 & of \\
\hline 1 & 0 & 0 & $0 \mathrm{e}$ & 0 & of \\
\hline 1 & 0.1 & 0 & $0 \mathrm{e}$ & 0 & of \\
\hline 1 & 0.5 & 0 & $0 \mathrm{e}$ & 0 & of \\
\hline 1 & 1 & 0 & $0 \mathrm{e}$ & 0 & of \\
\hline 2 & 0 & 0 & $0 \mathrm{e}$ & 0 & of \\
\hline 2 & 0.1 & 0 & $0 \mathrm{e}$ & 0 & of \\
\hline 2 & 0.5 & 0 & $0 \mathrm{e}$ & 0 & of \\
\hline 2 & 1 & 41.67 & $4 \pm 1 d$ & 30 & $5 \pm 0 \mathrm{e}$ \\
\hline 3 & 0 & 0 & $0 \mathrm{~d}$ & 0 & of \\
\hline 3 & 0.1 & 76.67 & $18.67 \pm 1.15 \mathrm{a}$ & 38.33 & $8 \pm 1 \mathrm{~b}$ \\
\hline 3 & 0.5 & 51.67 & $8.33 \pm 0.57 b$ & 81.67 & $19.33 \pm 0.57 \mathrm{a}$ \\
\hline 3 & 1 & 41.67 & $6.67 \pm 0.57 \mathrm{c}$ & 23.33 & $7 \pm 1 \mathrm{c}$ \\
\hline 4 & 0 & 0 & $0 \mathrm{e}$ & 0 & of \\
\hline 4 & 0.1 & 33.33 & $4.33 \pm 0.57 \mathrm{~d}$ & 17.67 & $6 \pm 1 \mathrm{~d}$ \\
\hline 4 & 0.5 & 0 & $0 \mathrm{e}$ & 0 & of \\
\hline 4 & 1 & 0 & $0 \mathrm{e}$ & 0 & of \\
\hline
\end{tabular}

Any two means that didn't share a common letter differ significantly from each other at $1 \%$ probability level.

showed that if we suppose that internal contamination exists in applied bulbs, this contamination would not spread all over the flake tissue; thus, at least some parts of the flake tissue would not be contaminated. Therefore, through cleaning or disinfecting (multistage), we can obtain intact explants from the flake tissue. Plant regeneration of the bulb explant from the Lilium species and other onion plants, such as tulipa and narcissus has been reported (Çig and Basdogan 2015). Sun et al. (2008) illustrated that the response of explant in the culture media is decreased when the bulb is utilized in the L. pumilium variety for organellation; a similar finding is reached in this study. A number of researchers (Bakhshaie 2010) reported that the bulb can be exploited to produce calluses and micropropagation of plants. This result is also consistent with a recent study. Micropropagation within the Lilium family has been applied only for the commercial species and it is rarely commodious for other Lilium species (Varshney et al. 2009). At low concentrations of auxin, the formation of perennial roots occurs, whereas at high concentrations of the root, auxin does not form and the callus tissue is formed. However, its concentration highly depends on the genotype and the content of the hormones in the explants. These requirements can be divided into three separate groups: a) those who only need auxin, b) those who need cytokine, and c) those who need both to form calluses. In this study, the 2,4-D hormone and kinetin were used with different concentrations in order to study callus formation. The effect of the 2,4-D hormone on the weight and diameter of the callus was significant. With an increase in the concentration of this hormone, the percentage of the callus formation decreased. When the 2,4-D concentration decreased, the average weight and diameter of callus increased. Bagheri and Saffari (2003) reported that the increase in auxin concentration increased the callus formation to a certain extent; when the increase is higher than an optimum level in the medium, it would have an inhibiting effect on the internal hormones of explants, which leads to a decrease in callus formation. The results indicated that for the formation of the callus of $L$. ledebourii, the sole existence of cytokinin is insufficient. There are also a few reports on cytokinin application (Zaidi et al. 2006). The essence of auxin and cytokine for the formation of the callus is desirable on $L$. ledebourii. Callus formation in an MS medium containing 
the hormone composition of 2,4-D and kinetin is considerable, especially in bulbs, which could be attributed to the endogenous auxin and cytokinin levels in the bulbs. On the other hand, by using a polar model, the auxin is transferred in the plants through a descending process (Lomax et al. 1995, Swarup and Bennett 2003). AbuRomman et al. (2013) explored the type of the plant growth regulator concentration that was produced during the combination of auxin and cytokinin, which has a significant trace on the frequency of the callus induction callus growth rate and the callus nature in cucumbers. The same results are achieved in this research as well. The concentration of the plant growth regulators in the culture media is very crucial for organ production. It was clearly shown that callus regeneration and its conversion to the stem or root mainly depend on auxin and cytokinin proportion in the medium (Thadavong et al. 2002). Organogenesis usually takes place when the cytokinin level exceeds the auxin level. However, the interaction of the endogenous and exogenous hormones causes differentiation of the tissue under the in vitro condition (Rout et al. 2006). Nhut (2003) also demonstrated that there is a direct relationship between the concentration of cytokinin and the formation of the organs. However, the current study showed that the presence of auxin and cytokinin is essential to induce shoots of bulb and a similar finding was reached by Jin et al. (2014). Internal auxin levels may be sufficient to produce callus. In this vein, the $L$. ledebourii onion may have adequate levels of the internal auxin hormone and can regenerate the shoot without additional external auxin. The auxins usually increase the organs of the maternal onion (Jin et al. 2014); those findings were similar to the results of this study. In this study, organogenesis from the callus tissue was observed in an MS culture containing 2,4-D $(3 \mu \mathrm{M})$ and kinetin $(0.1 \mu \mathrm{M})$. In the current study, at the beginning, there was a direct relation between the increase of the hormone and organ as well as the root generation; after a while, however, by increasing the concentration of hormones, the explant did not react. This finding proves that a significant relation existed between the dose of the hormones and the physiological response. When the hormone concentration increases, the physiological response will significantly increase until the plant reaches saturation point. Hence, this relation can be directed only before saturation point. This study also indicated that the presence of auxin and cytokinin is required to induce the stems by the bulb. This result is consistent with the findings of Jin et al. (2014). Thadavong et al. (2002) reported that regeneration of stem happened when there was a low proportion of auxin to cytokinin, while the root formation was performed at a high proportion of auxin to cytokinin. This is inconsistent with results of this study. The main reason for this discrepancy is the fact that the amount of the endogenous cytokinin hormone of $L$. ledebourii Bioss bulb is adequate and the addition of exogenous cytokinin leads to hormone imbalance. Islam et al. (2004) also found that the plant's potential for regeneration from the callus depended on the variety as well as the induction environment. Ilahi et al. (2005) stated that the organogenesis potential of the callus tissue depended on the plant species, type of explants from which the callus is taken, callus age, and the nutrition in the medium. Another important factor is the type of the different growth regulators. The rapid success in organogenesis probably depends on the potential of plant tissue for natural regeneration. Tang et al. (2010) reported that the best environment for the regeneration of $L$. leucantum from the flake explants is an MS medium containing $0.5 \mu \mathrm{M}$ BA along with $3 \mu \mathrm{M}$ 2,4-D, which is not consistent with the results of this study. On the other hand, Bacchetta et al. (2003) illustrated that the organ generation requires a BA hormone. The gene pathway of the BA hormone in the onion of L.ledebourii is probably non-active. This trait results in a) an improper physiological response and b) the differentiation between the L. ledebourii plant and other plants of the Lilium family. In this study, the increase in 2,4-D leads to an increase in root formation. This shows the dominance of the effect of the auxin over the effect of cytokinin in rooting. Pierik (1998) also pointed out that the low concentrations of cytokinin stimulate cell division, while higher concentrations prevent root irritation. This study contended that auxin can induce long shoots through cell elongation.

\section{Acknowledgment}

I warmly thank the staffs and managers of Iranian Biological Resource Center for providing necessary facilities to do this study.

\section{Compliance with ethical standards}

Conflict of interest The authors declare that they have no conflict of interest.

Author contribution statement SGH Conceived and designed research, wrote manuscript and acted as corresponding 
author. BAF and MRN Supervised development of work, analyzed the data, helped in data interpretation and manuscript evaluation. NMN Conducted experiments, contributed new reagents and drafted the manuscript. All authors read and approved the final manuscript.

\section{References}

Abu-Romman S, Suwwan, M, and Al-Ramamneh, E. (2013) The influence of plant growth regulators on callus induction from hypocotyls of cucumber (Cucumis sativus L.). Advances in Environmental Biology, 7(2):339-343

Arzate FAM, Nakazaki T, Qkumato T, and Tanisaka T. (1997) Efficient callus induction and plant regeneration from filaments with anther in lily (Lilium longiflorum Thunb). Plant Cell Rep 16(12):836-840

Azadi P. (2003) Effect of growth regulators, sucrose concentration and scale pieces on micropropagation of Chelcheragh lily (Lilium ledebourii) in spring season. Proceedings of the 2nd Sci and Applied Seminar on Ornamental Plants, P 43

Azadi P, and Khosh-Khui M. (2007) Micropropagation of Llilium ledebourii (Baker) Bioss as affected by plant growth regulator, sucrose concentration, harvesting season and cold treatments. Electronic Journal of Biotech 10(4):582-591

Bacchetta L, Remotti, PC, Bernardini C, and Saccardo F. (2003) Adventitious shoot regeneration from leaf explants and stem nodes of Lilium. Plant Cell Tissue Organ Cult. 74:37-44

Bagheri A, Saffari M (2003) In Vitro Culture of Higher Plants. Translate. 4th Edition. Ferdowsi University of Mashhad. 406 $\mathrm{pp}$

Bakhshaie M, Babalar M, Mirmasoumi M, and Khalighi A. (2010) Somatic embryogenesis and plant regeneration of Lilium ledebourii (Baker) Boiss, an endangered species. Plant Cell Tissue Organ Cult. 102:229-235

Chang C, Chen CT, Tasi YC, and Chang WC. (2000) A tissue culture protocol for propagation of a rare plant, Lilium speciosum Thunb. var. gloriosoides Baker. Botari cal Bulletin of Academic Sinica 41:139-142

Chawla HS. (2000) Introduction to Plant Biotechnology, Science Publishers, pp 368

Chawla HS. (2002) Introduction to Plant Biotechnology, Science Publishers, pp 538

Çiğ A, and Başdoğan G. (2015) In vitro propagation techniques for some geophyte ornamental plants with high economic value, International Journal of Secondary Metabolite. 2(1):27-49

Eudes F, Acharya S, Laroche A, Selinger LB, and Cheng KJ. (2003) Novel method to induce direct somatic embryogenesis, secondary embryogenesis and regeneration of fertile green cereal plants. Plant Cell, Tissue and Organ Culture, 73: 147-157

Gholami M. (2007) Micropropagation of of inverted tulip (Fritillaria imperialis L.). MSc. Thesis, University of Avicenna. Hamedan, Iran. Pp 69
Ilahi I, Bano S, Jabeen M, and Rahim F. (2005) Micropropagation of rice (Oryza sativa L. cv. SWAT-II) through somatic embryogenesis. Pak J Bot 37(2):237-242

Islam MM., Wahed SA., Khan SAKU. (2004). Studies on callus induction and regeneration from dehusked rice (Oryza sativa L.) seeds. Plant Tissue Cult 14(2):155-160

Jin S, Wang J, Wang X, and Liu S. (2014) Direct and indirect shoot and bulblet regeneration from cultured leaf explants of Lilium pumilum, an endangered species, In Vitro Cellular and Developmental Biology -Plant, 50:69-75

Kamo K, and Hee Han B. (2012) Optimized groeth and plant regeneration for callus of Lilium Longflorum 'Nellie White'. Floriculture and Ornamental Biotech 6(2):94-98

Kanchanapoom K, Ponpiboon T, Wirakiat W, and Kanchanapoom K. (2011) Regeneration of lily (Lilium longiflorum 'Easter lily') by callus derived from leaf explants cultured in vitro. Sci Asia 37:373-376

Lomax TL, Muday GK, and Ruberty PH. (1995) Auxin transport. In plant hormones: physiology,biochemistry and molecular in plant hormones: physiology, biochemistry and molecular biol (Davies, P.J., ed.). Dordrecht: Kluwer Academic Publishers pp 509-530

Mohamadi-Dehcheshmeh M. (2005) Using tissue culture techniques in the reproduction of endangered species of theinverted tulip native to Iran. MSc. Thesis, Tehran University. Tehran, Iran

Mori S, Adachi Y, Horimoto S, Suzuk A, and Nakano M. (2005) Callus formation and plant regeneration in various Lilium species and cultivars. In Vitro Cell Dev Biol - Plant 41: 783-788

Murashige T, and Skoog F. (1962) A revised medium for rapid growth and bioassay with tobacco tissue culture. Phisiol planta 15:97-473

Nhut DT. (2003) The control of in vitro direct main stem formation of Lilium longiflorum derived from receptacle culture and rapid propagation by using in vitro stem nodes. Plant Growth Regulation 40(2):179-184

Padasht Dahkaei MN. (2005) The investigation of different methods for culturing and propagarion of Chelcheragh lily (Lilium ledebourii), native of Iran, and its introduction possibility as a new floricultural crop. Ph. D. Thesis, Islamic Azad University, Science and Research Unit, Tehran, Iran pp 120

Pierik, RLM. (1987). In vitro Culture of Higher Plants. springer, $311 \mathrm{PP}$

Rout G, Mohapatra A, and Mohan S. (2006) Tissue culture of ornamental pot plant: A critical review on present scenario and future prospects Biotech Adv 24:531-560

Saetiew K, and Umamanit T. (2015) Micropropagation of Lilium formolongo via leaf explants. Journal of agricultural Technol 11(4):855-862

Simmonds JA, and Cumming BG. (1976). Propagation of Lilium Hybrids. II. Production of plantlets from bulb-scale callus culture for increased propagation rates. Scientia Hortic 5: $161-170$

Skoric M, Zivkovic S, Savic J, Siler B, Sabvoljevic A, Todorovic., 
Sladjana.,and Grubisic D. (2012) Efficient one-step tissue culture protocol for propagation of endemic plant, Lilium martagon var. cattaniae Vis. African journal of Biotech 11(8): 1862-1867

Sun XC, Guang FC, Huang CY, and Liu DY. (2008) Study on the subculture, root induction and transplanting technique of low lily. Hebei J. For. Orchard Res. 23:211-213

Swarup R, Bennett M (2003) Auxin transport: the fountain of life in plants; Dev Cell 5:824-826

Tang YP, Liu XQ, Wahiti Gituru R, and Chen LQ. (2010) Callus Induction and Plant Regeneration from in vitro cultured leaves, Petioles and scales of Lilium Leucanthum (Baker) Baker. Biotechnology and Biotechnological Equipment 24(4): 2071-2076
Thadavong S, Sripichitt P, Wongyai W, and Jompuk P. (2002) Callus induction and plant regeneration from mature embryos of glutinous rice (Oryza sativa L.) cultivar TDK1. Kasetsart Journal 36(4):334-344

Varshney A, Dhawan V, and Srivastava PSA. (2000) protocol for in vitro mass propagation of Asiatic hybrids of lily through liquid stationary culture. In Vitro Cell. Dev. Biol. Plant 36: 383-391

Zaidi MA, Narayanan M, Sardana R, Taga I, Postel S, Johns R, McNulty M, Mottiar Y, Mao J, Loit E, and Altosaar I. (2006) Optimizing tissue culture media for efficient transformation of different indica rice genotypes. Agronomy Res 4(2): 563-575 